Wilk A, Specht C, Koc W, et at. Correction of determined coordinates of railway tracks in mobile satellite measurements. Diagnostyka.

\title{
CORRECTION OF DETERMINED COORDINATES OF RAILWAY TRACKS IN MOBILE SATELLITE MEASUREMENTS
}

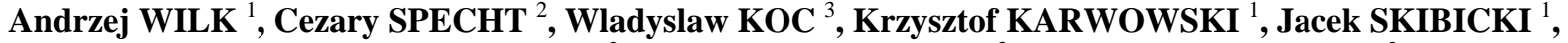 \\ Krzysztof CZAPLEWSKI ${ }^{2}$, Piotr CHROSTOWSKI ${ }^{3}$, Pawel S. DABROWSKI ${ }^{2}$, \\ Slawomir GRULKOWSKI ${ }^{3}$, Slawomir JUDEK ${ }^{1}$, Mariusz SPECHT ${ }^{2}$, Jacek SZMAGLIŃSKI ${ }^{3}$ \\ ${ }^{1}$ Gdańsk University of Technology, Faculty of Electrical and Control Engineering, Narutowicza 11/12 str., \\ 80-233 Gdańsk, Poland, e-mail: andrzej.wilk@pg.edu.pl, krzysztof.karwowski@pg.edu.pl, \\ jacek.skibicki@pg.edu.pl, slawomir.judek@pg.edu.pl, \\ ${ }^{2}$ Gdynia Maritime University, Department of Geodesy and Oceanography, Morska 81-87 str., 81-225 Gdynia, \\ Poland, e-mail c.specht@wn.umg.edu.pl, k.czaplewski@wn.umg.edu.pl, p.dabrowski@wn.umg.edu.pl, \\ m.specht@wn.umg.edu.pl \\ ${ }^{3}$ Gdańsk University of Technology, Faculty of Civil and Environmental Engineering, Narutowicza 11/12 str., \\ 80-233 Gdańsk, Poland, e-mail: wladyslaw.koc@pg.edu.pl, piotr.chrostowski@pg.edu.pl, \\ slawomir.grulkowski@pg.edu.pl, jacek.szmaglinski@pg.edu.pl
}

Abstract

This article examines one of the basic issues related to the technique of mobile satellite measurements in railway tracks. This problem concerns the correction of the determined coordinates of the track centerline. The need to perform this operation results from the GNSS receivers positioning at a certain height above the level of the existing track axis, leading to longitudinal and lateral shifts of antennas. The key problem here is the determination of the local horizontal coordinate system in each measured position. For the analysis, the authors defined the directional baseline vector of the measuring platform on the basis of positions given by two satellite antennas, positioned over the pivots of its bogies. This work presents the procedure for determining the corrections values.

Keywords: Track geometric layout, GNSS/INS/MLS measurements, RTK measurements, Data processing

\section{KORYGOWANIE WYZNACZONYCH WSPÓŁRZĘDNYCH OSI TORU KOLEJOWEGO W MOBILNYCH POMIARACH SATELITARNYCH}

Streszczenie

$\mathrm{W}$ pracy poruszono jedną $\mathrm{z}$ podstawowych kwestii związanych $\mathrm{z}$ techniką mobilnych pomiarów satelitarnych w torze kolejowym - korygowanie wyznaczonych współrzędnych osi toru. Konieczność przeprowadzenia tej operacji wynika $\mathrm{z}$ ustawienia anten GNSS na pewnej wysokości nad poziomem istniejącej osi toru, przy występowaniu jego pochylenia w kierunku podłużnym i poprzecznym. Kluczowym problemem staje się przy tym konieczność określania w każdym punkcie pomiarowym kierunków osi układu współrzędnych w płaszczyźnie poziomej. W omawianej metodzie posłużono się kierunkowym wektorem bazowym, wyznaczonym na podstawie współrzędnych anten usytuowanych nad czopami skrętów obydwu wózków platformy. W pracy przedstawiono procedurę określania wartości korekt.

Słowa kluczowe: Układ geometryczny toru, Pomiary GNSS/INS/MLS, Pomiary mobilne RTK, Przetwarzanie danych

\section{INTRODUCTION}

The speeds of trains travelling on operated railway lines and their safety are closely related to the designed and existing shape of the track axis the centerline.

Considering the fact that, during line exploitation, its shape deforms horizontally and vertically, its continuous monitoring and diagnostics is a crucial element of its management system. So far, the maximum allowed speed on a given section of the line is primarily established based on the assessment of the rails' deformation, i.e. on track irregularities. Such analysis is based on various quality indices, which are calculated from the measurements of horizontal and vertical versines, related to a specific chord $[1-5,7,13]$.

However, direct shape assessment using absolute track geometry (ATG) has not been widely used until recently. The reason for this was primarily the lack of a possibility for an unambiguous and efficient way of referring the track axis to the coordinates of the geodetic control networks, or, in general, to the designed track coordinates. In the last decade, railway control networks located along the tracks have been 
commonly introduced. The control marks enable the measurement units to identify the spatial coordinates of the track axis. Regardless of the measurement method, the accuracy of the control points' determination and the issue of its maintenance remains an important problem. This situation also occurs in the method of determining the track axis using mobile total stations (introduced in recent years and already widely used), allowing quasi-continuous registration of spatial positions. The measurements are carried out - as mentioned - in relation to a specially created railway geodetic control network, established with the use of a high accuracy global navigation satellite system (GNSS) [6].

The new technologies in modern surveying enable operating with ATG without the necessity of linking the measurement system to the track survey markers. As has been proven in [6], real-time kinematic (RTK) GNSS surveying, integrated with inertial measurements, deliver global coordinates, which can be used in the estimation problem of the track axis. In [6], the integrated multi-sensory trolley (pushed by human force) has been presented, and the algorithm therein regards the integration of satellite and inertial signals (also with the signals of track irregularity). Compared to that study, the authors of presented article discuss the algorithms adopted to the mobile satellite measurement method (MSM) [14]. This means that the measurement is carried out at higher speeds in relation to the cited surveying method, and the measured (in RTK mode) positions need to be recalculated in order to obtain the position of the track axis. In this article, the specific corrections defined on the basis of the track-train system geometry analysis have been presented.

Operating in a global coordinate system (in Poland, PL-2000) means that the correction of the determined coordinates of the existing track axis requires the determination of the coordinate axes directions at each measuring point in the horizontal plane - which, in the case of tracks located in the arc, can be difficult. In addition, in each method, it is necessary to take into account the offset of the measuring device relative to the theoretical position of the track axis - i.e. the point of symmetry at the height of the line connecting the rolling surfaces of the rail heads.

A fixed offset of the recording device relative to the track axis occurs only on straight sections, where the coordinate measurement can be directly identified with the existing track axis, and then compared with the design axis. On the other hand, the coordinates of the track axis determined on the sections located in the arc depend not only on the location of the measuring device relative to the rails, but also on the value of the track cant. By definition, the track cant is the height difference between the rails in individual cross-sections. The cant is usually made by lifting the outer rail relative to the inner rail by the design value. This value can have a constant distribution - along the length of the circular arc - or a variable distribution - along the transition curves (cant transitions). In each variant, it causes the designed track centerline to be shifted inwards as a result of the rotation of the entire track structure, relative to a certain reference point.

To avoid the centerline's offset, the cant can be constructed by rotating the track with respect to the point belonging to the centerline. This would mean that outer rail is lifted, while the inner rail should be stabilized beneath its initial level. Such a way of creating the cant is very difficult, so this variant is rarely seen in practice. For those reasons, the authors have taken into account both corrections, i.e. resulting from the GNSS antennas placement, and resulting from the track cant.

The method presented in this work is based on the thoughtful positioning of GNSS receivers relative to the measurement platform. To determine corrections for the measured horizontal coordinate signal, the authors developed an algorithm based on track inclination measurements.

\section{TECHNIQUE OF MOBILE SATELLITE MEASUREMENTS}

The main idea of the technique of mobile satellite measurements (MSM) [8, 10, 11, 14], developed since 2009 by the Gdańsk University of Technology and the Naval Academy/Maritime University of Gdynia, is measuring railways with the use of GNSS antennas installed over the bogie pivots of a measuring wagon. The recorded satellite signals are analyzed and, on that basis, the existing railway centerline is calculated.

The MSM method, from the point of view of efficiency, surpasses other stationary and quasimobile techniques (i.e. with measuring carts manually pushed by the operator) $[9,15]$. This is due to the simple fact that real-time positioning (RTK) does not require linking with the geodetic survey markers (such as in the case of tacheometry). Moreover, a sufficiently high frequency of recording samples (normally $20 \mathrm{~Hz}$ ) allows the track to be measured with a relatively high speed. In addition, the accuracy of GNSS measurements - due to the dynamic development of satellite infrastructure - promises to develop effective inventory methods, as well as methods for developing track axis adjustment projects. The major advantages of this method are its mobility, speed of measurement, high accuracy of positions determination, and no need to perform relatively complex transformations to calculate the positions. Compared to tacheometry, this method does not require building and maintaining geodetic control networks. The basic application difficulties result from the technological advancement of the measuring apparatus (availability, service) and the need to operate with large amounts of measurement data. 
In the MSM method, the GNSS antennas are positioned at a fairly significant height (about $1.5 \mathrm{~m}$ ) above the level of the existing track. Therefore, it becomes necessary to correct the determined coordinate values. The decisive role is played by the measurement of the longitudinal and lateral track inclination with the additionally installed inclination measuring system. The issue of determining the directions of the coordinate system in a horizontal plane at each measuring point is solved in the discussed method by analyzing the directional baseline vector of the measuring wagon, determined by two satellite antennas installed above the bogie pivots. Figure 1 shows the concept of the measuring platform. The system consists of the $401 \mathrm{Z}$ platform wagon and the measurement set of two RTK GNSS receivers. The distance between receivers established on a wagon's base as a distance between bogie pivots is $l_{b}$.

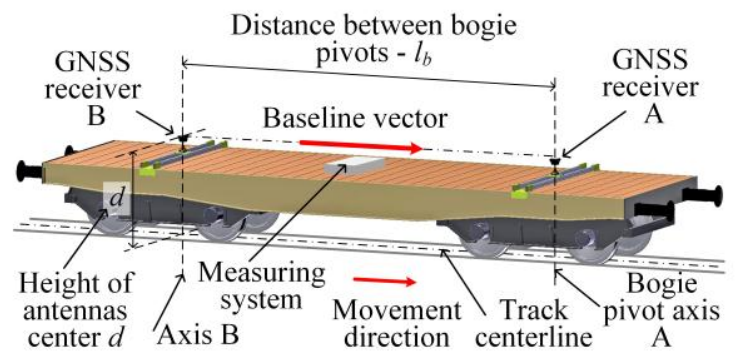

Fig. 1. A schematic view of the measuring platform

\section{ASSUMPTIONS OF THE CORRECTION METHOD}

The direct measurement of the track centerline positions is difficult to perform. Only static manual methods allow the measurement device to be positioned at the level of the rails' surface. In the aforementioned MSM method, there is no possibility to do this. The GNSS antenna's center is located at a certain fixed height relative to the rails. This height results from the dimensions of the measuring wagon and the dimensions of the antenna's supporting system, as well as from the antenna's height. Consequently, the antenna deviates from the reference position due to the longitudinal and lateral track inclinations. In this situation, the satellite coordinates of the track axis are subject to an error that should be unconditionally eliminated. Appropriate correction of coordinates recorded by GNSS receivers can be performed by the measurement of the wagon frame inclinations. The inclination of the immediate vicinity of GNSS receivers was measured using inclinometers (Fig. 1, 7).

In the presented algorithm, the full set of data for a given measuring point is as follows:

- recording time $t$,

- horizontal and vertical coordinates in global Cartesian coordinate system (PL-2000),
- inclination angles $\alpha_{v}$ and $\alpha_{t}$ of longitudinal and lateral directions respectively.

The signal of antenna on the front bogie (marked as GNSS receiver A) will be use to correct the track centerline coordinates. The signal consists of $Y_{A}\left(t_{k}\right), X_{A}\left(t_{k}\right)$ and $H_{A}\left(t_{k}\right)$ coordinates which are recorded in time $t_{k}$, where $k=1,2, \ldots$ Firstly, a correction will be performed for the longitudinal inclinations, which results in new-calculated coordinates $\bar{Y}_{A}\left(t_{k}\right), \bar{X}_{A}\left(t_{k}\right), \bar{H}_{A}\left(t_{k}\right)$. Afterward, the lateral corrections will be made, and the final coordinates will be defined as $\overline{\bar{Y}}_{A}\left(t_{k}\right), \overline{\bar{X}}_{A}\left(t_{k}\right)$, $\overline{\bar{H}}_{A}\left(t_{k}\right)$.

\section{DETERMINATION OF THE BASELINE VECTOR OF THE MEASURING VEHICLE}

One of the key elements of the above algorithm for centerline correction is the measuring base. This base is defined in respect to the wheelbase of a wagon. In the case of the $401 \mathrm{Z}$ wagon, the wheelbase is between the bogies' pivots. While driving the measuring wagon, both extreme points of the measuring base change their position in the global coordinate system. However, the ends of the vector described on these points are permanently related to the track centerline. Moreover, this vector does not change its length due to the rigidity of the wagon platform. Mounting GNSS antennas directly above the bogie pivots allows the position of the baseline vector in the global coordinate system to be recorded.

In the given position of the frontal bogie, the horizontal coordinates $Y_{A}\left(t_{k}\right)$ and $X_{A}\left(t_{k}\right)$ of antenna A are determined. At the same time, antenna B (above the pivot of the second bogie) is located at the point of coordinates $Y_{B}\left(t_{k}\right)$ and $X_{B}\left(t_{k}\right)$.

The correctness of determining the horizontal coordinates of both A and B antennas can be easily verified by calculating the length of the baseline vector between them, using the formula:

$$
L_{b}=\sqrt{\left[Y_{B}\left(t_{k}\right)-Y_{A}\left(t_{k}\right)\right]^{2}+\left[X_{B}\left(t_{k}\right)-X_{A}\left(t_{k}\right)\right]^{2}}
$$

The result can be compared with a real construction dimension $l_{b}$ (measured using a high-precision tacheometer and class 1 measuring tape) between both bogies' pivots of the given wagon (Fig. 1).

Knowing the coordinates of antennas $Y_{A}\left(t_{k}\right)$ and $X_{A}\left(t_{k}\right)$ as well as $Y_{B}\left(t_{k}\right)$ and $X_{B}\left(t_{k}\right)$, the equation of the baseline vector can be defined in a global system of references at every moment of measuring time $t_{k}$.

\section{CORRECTION FOR LONGITUDINAL TRACK INCLINATION}

The rule of determining the correction for GNSS receiver position due to the longitudinal track inclination is illustrated in Fig. 2. 
Figure 2 shows that the values of corrections $\Delta H_{\mathrm{v}}$ and $\Delta L_{\mathrm{v}}$ for antenna position depends on the constructively determined height $d$ of the center antenna above the track plane, and the longitudinal inclination angle $\alpha_{v}\left(t_{k}\right)$, measured successively by the inclinometer. It is assumed that, in the case of a positive inclination (elevation), the angle $\alpha_{v}$ is positive (Fig. 2), and in the case of a negative inclination (slope), the $\alpha_{v}$ is negative. The horizontal and vertical correction can be calculated as follows:

$$
\begin{gathered}
\Delta L_{v}\left(t_{k}\right)=d \cdot \sin \alpha_{v}\left(t_{k}\right) \\
\Delta H_{v}\left(t_{k}\right)=\left(1-\cos \alpha_{v}\left(t_{k}\right)\right) \cdot d
\end{gathered}
$$

The final vertical correction toward the track level will be done in the next step.

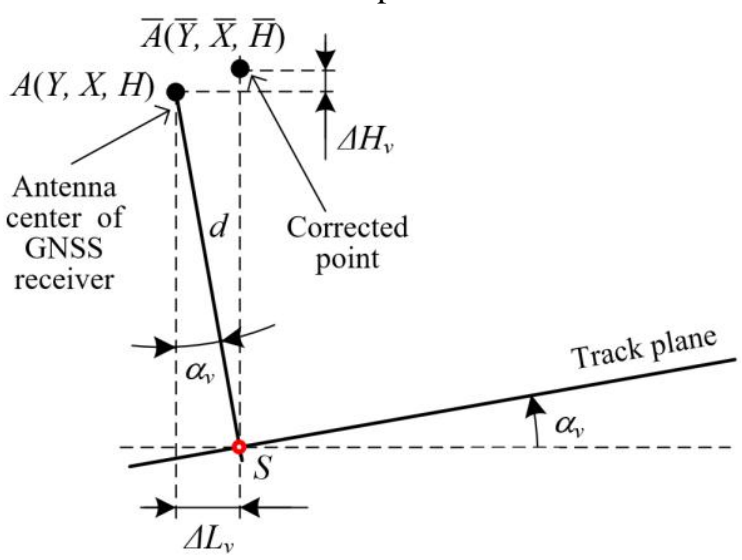

Fig. 2. GNSS receiver's location on the longitudinal track inclination for positive values of $\alpha_{v}$, measured coordinates $A(Y, X, H)$ and corrected coordinates $\bar{A}(\bar{Y}, \bar{X}, \bar{H})$

As can be seen, in the case of the $\Delta L_{v}$ correction defined by (2), the sign of the inclination (positive or negative), determined by the sign of angle $\alpha_{v}$, plays an important role. This correction is positive (i.e. shifting the measured $Y, X$ coordinates in the direction of movement of the wagon base) if the inclinometer indicates that $\alpha_{v}>0$. Otherwise, the $\Delta L_{v}$ correction has a negative value. The momentary sign of longitudinal inclination is determined in the discussed method by analyzing the baseline vector of the measurement platform. The altitude (vertical) correction $\Delta H_{v}$, described by (3), is positive in each case.

Figure 3 shows the dependence between the longitudinal inclination of the track and the discussed corrections. The corrections were calculated for the height of the antenna's center (in relation to the track) $d=1500 \mathrm{~mm}$.

It should be noted that, for a typical railway line, the maximum longitudinal inclinations usually do not exceed $10 \%$, which corresponds to $\alpha_{v}=$ $0.573^{\circ}$. For such a slope, the correction value $\Delta L_{v}$ is about $15 \mathrm{~mm}$. Regarding the correction in the longitudinal direction $\Delta H_{v}$, in the vast majority of cases, its value does not exceed 1 millimetre, and can be omitted.
Knowing this, the correction $\Delta L_{v}$ is not sufficient to directly determine the coordinates $\bar{Y}_{A}\left(t_{k}\right)$ and $\bar{X}_{A}\left(t_{k}\right)$. For this purpose, the differences of the abscissa $\Delta Y_{v}$ and the ordinates $\Delta X_{v}$ and their signs are needed.

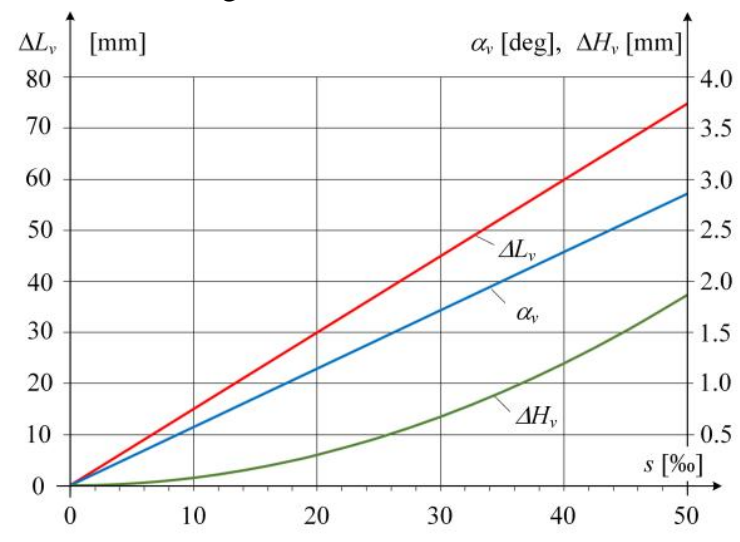

Fig. 3. The range of changes in the calculated values of $\Delta L_{v}$ and $\Delta H_{v}$ for various longitudinal slopes $s$

For determining the corrected coordinates of the track axis on the basis of the correction values in the longitudinal direction, the linear equation of the measuring base should be used, which shows that:

$$
\Delta X_{v}\left(t_{k}\right)=\frac{X_{B}\left(t_{k}\right)-X_{A}\left(t_{k}\right)}{Y_{B}\left(t_{k}\right)-Y_{A}\left(t_{k}\right)} \Delta Y_{v}\left(t_{k}\right)=a\left(t_{k}\right) \Delta Y_{v}\left(t_{k}\right)
$$

where: $a\left(t_{k}\right)$ - gradient of a line estimating the measuring vector.

Moreover, the following condition applies:

$$
\Delta Y_{v}^{2}+\Delta X_{v}^{2}=\Delta L_{v}^{2}
$$

Which, after taking into account (2) and (4), gives:

$$
\begin{gathered}
\Delta Y_{v}= \pm\left|\frac{d \cdot \sin \alpha_{v}\left(t_{k}\right)}{\sqrt{1+a^{2}\left(t_{k}\right)}}\right| \\
\Delta X_{v}= \pm\left|a\left(t_{k}\right) \frac{d \cdot \sin \alpha_{v}\left(t_{k}\right)}{\sqrt{1+a^{2}\left(t_{k}\right)}}\right|
\end{gathered}
$$

Determination of the sign in expressions (6) and (7) depends on the direction of the following measurement and the longitudinal inclination angle. Calculations of the corrected coordinates $\bar{Y}_{A}\left(t_{k}\right)$ and $\bar{X}_{A}\left(t_{k}\right)$ are presented in a Section 7 .

\section{CORRECTION FOR SUPERELEVATION TRACK INCLINATION}

The track inclination in the lateral direction results from the difference in rail levels. In structural terms, this difference is generated by tilting the sleepers (relative to the horizontal plane) by the angle $\alpha_{t}\left(t_{k}\right)$. It is assumed that the angle translates directly into the tilt of the measuring wagon surface, and can be measured by the inclinometers. It is also assumed that $\alpha_{t}\left(t_{k}\right)$ is positive when the right rail is elevated from zero level (according the direction of travel). In the opposite case, the sign is negative. The geometric 
relations between track cant and corrections are illustrated in Fig. 4.

As was previously described, inclination angle $\alpha_{t}$, from the implementation point of view, results from the rotation of the sleeper around the line of contact between the sleeper's head's lower edge and the ballast layer. In a cross-section, this rotation axis is represented by point $O$. The center of the sleeper's bottom, point $S_{1}\left(l_{p} / 2,0\right)$, moves to point $S_{2}$ $\left(x_{S 2}, y_{S 2}\right)$. The equation for the straight line where $S_{2}$ lies is:

$$
y=x \cdot \tan \alpha_{t}\left(t_{k}\right)
$$

At this point, it should be noted that the values of corrections $\Delta L_{t}$ and $\Delta H_{t}$ are significantly influenced by the superstructure elements, i.e. the type of sleeper and rail, as well as the way the rail is fastened to the sleeper. The dimensions of the sleeper are also crucial, especially its length $l_{p}$ and height in the place of the rail's positioning. The last dimension, in combination with the rail's height (together with the fastening system), determines the position of the upper surface of the rail's head relative to the bottom of the sleeper (marked as $w-$ Fig. 4).

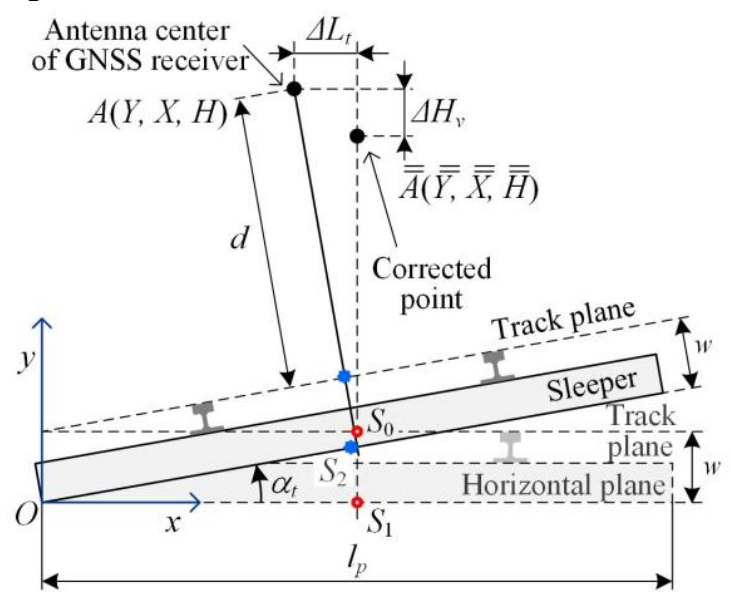

Fig. 4. Receiver's location in the track crosssection for positive values of $\alpha_{\mathrm{t}}$ and measured coordinates $A(Y, X, H)$ and corrected coordinates $\overline{\bar{A}} \overline{\bar{Y}}, \overline{\bar{X}}, \overline{\bar{H}})$ (for longitudinal inclination $\alpha_{v}=0$ )

Taking into account the equation (8) and the condition regarding the distance between the center of the sleeper's bottom and the point $O$, we can determine the coordinates of the point $S_{2}$ (Fig. 4):

$$
x_{S 2}=\frac{1}{\sqrt{1+\tan ^{2} \alpha_{t}\left(t_{k}\right)}} \frac{l_{p}}{2}, y_{S 2}=\frac{\tan \alpha\left(t_{k}\right)}{\sqrt{1+\tan ^{2} \alpha_{t}\left(t_{k}\right)}} \frac{l_{p}}{2}
$$

Thus, the equation of the perpendicular line to the straight line from (8), passing through point $S_{2}$, can be calculated as follows:

$$
y=y_{S 2}+\frac{1}{\tan \alpha_{t}\left(t_{k}\right)} x_{S 2}-\frac{1}{\tan \alpha_{t}\left(t_{k}\right)} x
$$

The highest point of the antenna $\mathrm{A}$, at a distance $w+d$ from point $S_{2}$ (Fig. 4), lies on the straight line (10). After transforming the equations, the coordinates of the satellite antenna's center can be calculated:

$$
\begin{aligned}
& x_{A}=\frac{1}{\sqrt{1+\tan ^{2} \alpha\left(t_{k}\right)}}\left[\frac{l_{p}}{2}-(w+d) \cdot \tan \alpha\left(t_{k}\right)\right] \\
& y_{A}=\frac{1}{\sqrt{1+\tan ^{2} \alpha\left(t_{k}\right)}}\left[\frac{l_{p}}{2} \tan \alpha\left(t_{k}\right)+(w+d)\right]
\end{aligned}
$$

Figure 4 indicates, that:

$$
\Delta L_{t}=\frac{l_{p}}{2}-x_{A}, \Delta H_{t}=-\left(y_{A}-w\right)
$$

When the right rail of the track is elevated (looking in the direction of movement), as in Fig. 4, the correction $\Delta L_{t}$ is positive (shifted to the right) and the correction $\Delta H_{t}$ is negative. Otherwise, i.e. when the cant increases towards the left rail, both $\Delta L_{t}$ and $\Delta H_{t}$ corrections are negative.

The determination of the impact of the track lateral inclination for the required correction of track axis coordinates, assuming $d=1500 \mathrm{~mm}$, $l_{\mathrm{p}}=2600 \mathrm{~mm}$ and $w=385 \mathrm{~mm}$, is shown in Fig. 5 .

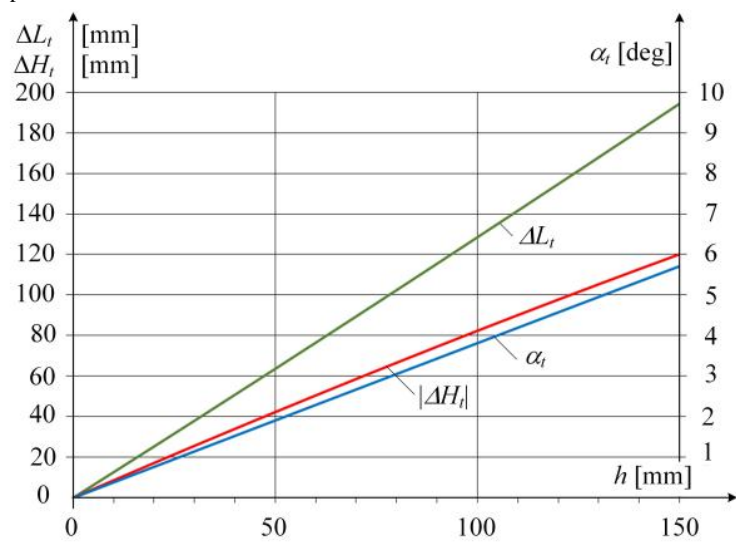

Fig. 5. Range of calculated values of $\Delta L_{t}$ and $\left|\Delta H_{t}\right|$ for different cant values $h$

As in the case of the longitudinal direction, even if the $\Delta L_{t}$ correction would have been know, it is not sufficient to determine the coordinates $\overline{\overline{Y_{A}}}\left(t_{k}\right)$, $\overline{\overline{X_{A}}}\left(t_{k}\right)$ directly. The values $\Delta Y_{t}$ and $\Delta X_{t}$ (of proper sign), together with the proper signs, should be determined. For determining the corrected coordinates of the track centerline based on the value of corrections in the cross-section, the equation of a straight line perpendicular to the baseline vector of the measuring wagon is used. In this case, the correction of the antenna's coordinates takes place in the direction of this perpendicular straight line. Using the equation of the baseline vector of the measuring wagon (4), the equation of the perpendicular direction passing through point $\mathrm{A}$ is defined as follows:

$$
\Delta X_{t}\left(t_{k}\right)=-a\left(t_{k}\right) \Delta Y_{t}\left(t_{k}\right)
$$

and the following condition applies:

$$
\Delta Y_{t}^{2}+\Delta X_{t}^{2}=\Delta L_{t}^{2}
$$

After implementing the equation (13) and the transformations, the formulas for $\Delta Y_{t}$ and $\Delta X_{t}$ are obtained: 


$$
\begin{gathered}
\Delta Y_{t}= \pm\left|\frac{\Delta L_{t}}{\sqrt{1+a^{2}\left(t_{k}\right)}}\right| \\
\Delta X_{t}= \pm\left|a\left(t_{k}\right) \frac{\Delta L_{t}}{\sqrt{1+a^{2}\left(t_{k}\right)}}\right|
\end{gathered}
$$

As in the case of formulas (6) and (7), the determination of the proper sign in expressions (15) and (16) is presented in chapter 7. As before, it depends on the measurement situation.

\section{CALCULATIONS OF CORRECTED TRACK COORDINATES}

For determining the corrected coordinates of the track centerline on the basis of the correction values in the longitudinal and lateral directions, the equation of the baseline vector of the measuring wagon was used. The correction of the antenna position in the longitudinal profile takes place in accordance with the direction of the straight line of the vector base, while the correction of the antenna position in the lateral direction takes place in accordance with the perpendicular straight line to the baseline vector.

The solution to the problem requires consideration of the measuring situation: the wagon moving on a rising or falling inclination in a certain direction. There are four possible variants here:

- run on a rising inclination (angle $\alpha_{v}>0$ ) according to the coordinate system $\left(Y_{A}\left(t_{k}\right)>Y_{B}\left(t_{k}\right)\right)$,

- run on a rising inclination $\left(\alpha_{v}>0\right)$ in the opposite direction to the coordinate system $Y$ $\left(Y_{A}\left(t_{k}\right)<Y_{B}\left(t_{k}\right)\right)$,

- run on a falling slope $\left(\alpha_{v}<0\right)$ according to the coordinate system $Y\left(Y_{A}\left(t_{k}\right)>Y_{B}\left(t_{k}\right)\right)$,

- run on a falling slope $\left(\alpha_{v}<0\right)$ in opposite direction to the coordinate system $Y$ $\left(Y_{A}\left(t_{k}\right)<Y_{B}\left(t_{k}\right)\right)$.

There can be two scenarios in the horizontal plane for each case:

- where ordinates $X$ are above $Y$ axis,

- where ordinates $X$ are below $Y$ axis.

Finally, in each scenario, two cases can be distinguished:

- cant ordinates refer to the right rail - in the direction of travel (positive cant, angle $\left.\alpha_{t}\left(t_{k}\right)>0\right)$,

- cant ordinates refer to the left rail - in the direction of travel (negative cant, angle $\left.\alpha_{t}\left(t_{k}\right)<0\right)$.

Taking into account the above conditions and formulae (6), (7), (15), and (16), 16 variants are obtained, which are listed in Table 1.

\section{EXAMPLE OF APPLICATION OF THE CALCULATION ALGORITHMS}

Research conducted with the use of MSM will determine the current and future prospects for using the discussed method in railways [11, 12, 14]. Figure 6 presents a view of the measuring platform during experimental measurements on the railway line No. 211, on the Chojnice-Brusy section, which was carried out by a multi-person research team.

Table 1. Variants of correcting coordinates

\begin{tabular}{|c|c|c|c|}
\hline \multicolumn{2}{|c|}{ Case 1 } & \multicolumn{2}{c|}{ Case 2} \\
\hline \multicolumn{2}{|c|}{$\alpha_{v}\left(t_{k}\right)>0$} & \multicolumn{2}{|c|}{$\alpha_{v}\left(t_{k}\right)>0$} \\
$Y_{A}\left(t_{k}\right)>Y_{B}\left(t_{k}\right)$ & \multicolumn{2}{c|}{$Y_{A}\left(t_{k}\right)<Y_{B}\left(t_{k}\right)$} \\
\hline$X\left(t_{k}\right)>0$ & $\Delta Y_{v}>0$ & $X\left(t_{k}\right)>0$ & $\Delta Y_{v}<0$ \\
$\alpha_{t}\left(t_{k}\right)>0$ & $\Delta Y_{t}>0$ & $\alpha_{t}\left(t_{k}\right)>0$ & $\Delta Y_{t}>0$ \\
\hline$X\left(t_{k}\right)>0$ & $\Delta Y_{v}>0$ & $X\left(t_{k}\right)>0$ & $\Delta Y_{v}<0$ \\
$\alpha_{t}\left(t_{k}\right)<0$ & $\Delta Y_{t}<0$ & $\alpha_{t}\left(t_{k}\right)<0$ & $\Delta Y_{t}<0$ \\
\hline$X\left(t_{k}\right)<0$ & $\Delta Y_{v}>0$ & $X\left(t_{k}\right)<0$ & $\Delta Y_{v}<0$ \\
$\alpha_{t}\left(t_{k}\right)>0$ & $\Delta Y_{t}<0$ & $\alpha_{t}\left(t_{k}\right)>0$ & $\Delta Y_{t}<0$ \\
\hline$X\left(t_{k}\right)<0$ & $\Delta Y_{v}>0$ & $X\left(t_{k}\right)<0$ & $\Delta Y_{v}<0$ \\
$\alpha_{t}\left(t_{k}\right)<0$ & $\Delta Y_{t}>0$ & $\alpha_{t}\left(t_{k}\right)<0$ & $\Delta Y_{t}>0$ \\
\hline
\end{tabular}

\begin{tabular}{|c|c|c|c|}
\hline \multicolumn{2}{|c|}{ Case 3} & \multicolumn{2}{c|}{ Case 4} \\
\hline \multicolumn{2}{|c|}{$\alpha_{v}\left(t_{k}\right)<0$} & \multicolumn{2}{c|}{$\alpha_{v}\left(t_{k}\right)<0$} \\
$Y_{A}\left(t_{k}\right)>Y_{B}\left(t_{k}\right)$ & \multicolumn{2}{c|}{$Y_{A}\left(t_{k}\right)<Y_{B}\left(t_{k}\right)$} \\
\hline$X\left(t_{k}\right)>0$ & $\Delta Y_{v}<0$ & $X\left(t_{k}\right)>0$, & $\Delta Y_{v}>0$ \\
$\alpha_{t}\left(t_{k}\right)>0$ & $\Delta Y_{t}>0$ & $\alpha_{t}\left(t_{k}\right)>0$ & $\Delta Y_{t}>0$ \\
\hline$X\left(t_{k}\right)>0$ & $\Delta Y_{v}<0$ & $X\left(t_{k}\right)>0$, & $\Delta Y_{v}>0$ \\
$\alpha_{t}\left(t_{k}\right)<0$ & $\Delta Y_{t}<0$ & $\alpha_{t}\left(t_{k}\right)<0$ & $\Delta Y_{t}<0$ \\
\hline$X\left(t_{k}\right)<0$ & $\Delta Y_{v}<0$ & $X\left(t_{k}\right)<0$, & $\Delta Y_{v}>0$ \\
$\alpha_{t}\left(t_{k}\right)>0$ & $\Delta Y_{t}<0$ & $\alpha_{t}\left(t_{k}\right)>0$ & $\Delta Y_{t}<0$ \\
\hline$X\left(t_{k}\right)<0$ & $\Delta Y_{v}<0$ & $X\left(t_{k}\right)<0$, & $\Delta Y_{v}>0$ \\
$\alpha_{t}\left(t_{k}\right)<0$ & $\Delta Y_{t}>0$ & $\alpha_{t}\left(t_{k}\right)<0$ & $\Delta Y_{t}>0$ \\
\hline
\end{tabular}

The research was carried out using the latest generation of GNSS measuring equipment, along with the reference station network existing in Poland. Various variants of the measurement system configuration were analyzed. A key role was played by the baseline vector determined by both the A and B antennas (Fig. 6). The measurement results will be processed in a

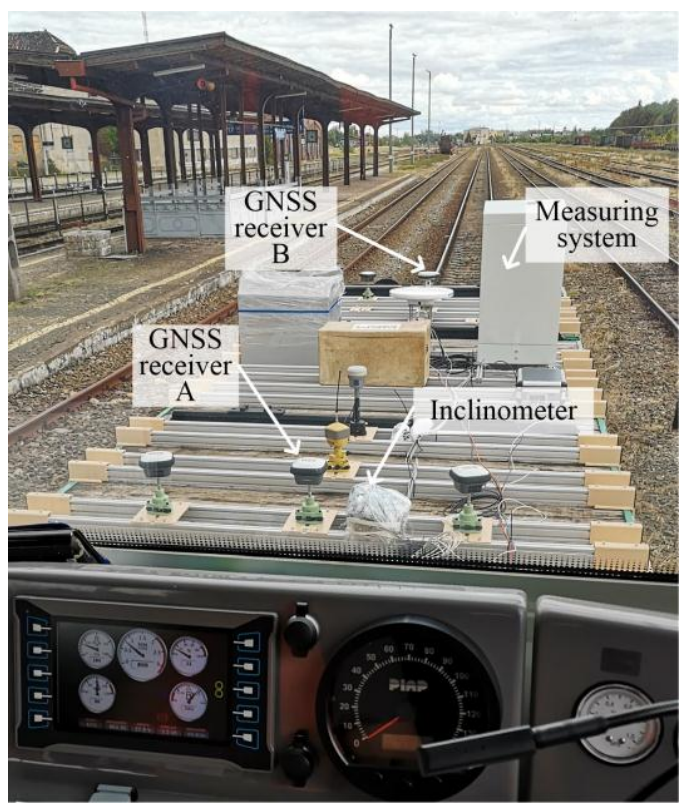

Fig. 6. The measuring platform during mobile measurements; GNSS receivers A and B define the baseline vector of the platform 
multilayer IT system developed as a part of the project, which will then allow the results to be presented in a functional web application.

Measurements were carried out with a constant speed of about $v=30 \mathrm{~km} / \mathrm{h}$. The results for the section comprising two circular arcs with transition curves separated by a straight section are shown in Fig. 7. The figure also shows the result of the correction procedure for measurement results due to the presence of lateral inclinations on the arcs.

Since the values of track axis position corrections do not exceed a few centimetres, the introduced correction is visible only on the enlarged fragment of the drawing. It covers an area of $2 \mathrm{m \times 2}$, in which the location of 7 sample measuring points with coordinates $Y\left(t_{k}\right), X\left(t_{k}\right)$ for $t_{k}-t_{k-1}=50 \mathrm{~ms}$ is recorded, which corresponds to the measuring frequency of $20 \mathrm{~Hz}$. Due to the nature of the cant, the track centerline corrected to the design position will always lie outside the curve relative to the measured one, as the enlarged fragment of Fig. 7 confirms.

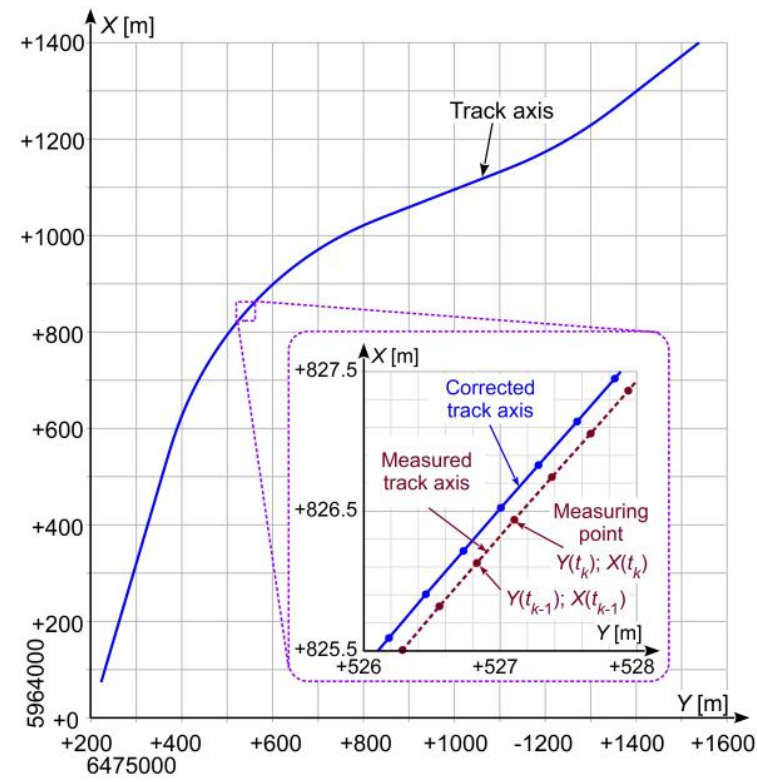

Fig. 7. An example of correction of the railway track axis using the MSM method

\section{SUMMARY}

The precise identification of a track centerline entails a number of possibilities related to the updating of digital data on the location of lines and engineering objects in the Cartesian coordinate system (in this study, the PL-2000 system was used). This data can also be used to plan, design, and build databases for infrastructure management.

The analysis carried out in this study showed that the correction values necessary to identify the designed track centerline reach several millimetres. Therefore, they are significant in comparison to the expected accuracy for this type of analysis (the order of $1 \mathrm{~cm})$. Therefore, the correction of inclinations cannot be omitted. The presented algorithm is fully universal in terms of varying shapes of tracks, and can be successfully used in the post-processing analysis of satellite signals. The key element of the algorithm is the baseline vector of the measuring wagon, which allows for the orientation of the corrections at any point of measurement.

The large number of measurement data obtained, resulting from a sampling rate of $20 \mathrm{~Hz}$, means that the coordinate correction process must be automated. The computational algorithms presented here make it possible to implement them in the form of an appropriate computer program.

\section{SOURCE OF FUNDING}

The project "Development of an innovative method for determining the precise trajectory of a railway vehicle" was financed by the European Regional Development Fund under the Smart Growth Operational Programme 2014-2020 (SGOP) and the resources of Polish Railways (PKP Polskie Linie Kolejowe S.A.). The project was implemented as part of the joint undertaking of the National Center for Research and Development and Polish Railways, "Research and Development in Railway Infrastructure." Project acronym: InnoSatTrack.

\section{REFERENCES}

1. Aceituno JF, Chamorro R, Muñoz S, Escalona JL. An alternative procedure to measure railroad track irregularities. Application to a scaled track. Measurement. 2019 Apr;137:417-27. https://doi.org/10.1016/j.measurement.2019.01.025

2. Akpinar B, Gülal E. Multisensor Railway Track Geometry Surveying System. IEEE Trans. Instrum. Meas. 2012 Jan;61(1):190-7.

https://doi.org/10.1109/TIM.2011.2159417

3. Akpinar B, Gülal E. Railway track geometry determination using adaptive Kalman filtering model. Measurement. 2013 Jan;46(1):639-45. https://doi.org/10.1016/j.measurement.2012.08.023

4. Andani MT, Peterson A, Munoz J, Ahmadian M. Railway track irregularity and curvature estimation using doppler LIDAR fiber optics. Proc Inst Mech Eng Part F J Rail Rapid Transit. 2018 Jan; 232(1):6372. https://doi.org/10.1177/0954409716660738

5. Chen Q, Niu X, Zhang Q, Cheng Y. Railway Track Irregularity Measuring by GNSS/INS Integration. Navigation. 2015 Mar;62(1):83-93. https://doi.org/10.1002/navi.78

6. Chen Q, Niu X, Zuo L, Zhang T, Xiao F, Liu Y, et al. A Railway Track Geometry Measuring Trolley System Based on Aided INS. Sensors. 2018 Feb 10;18(2):538. https://doi.org/10.3390/s18020538

7. Chiou S-B, Yen J-Y. Precise railway alignment measurements of the horizontal circular curves and the vertical parabolic curves using the chord method. Proc Inst Mech Eng Part F J Rail Rapid Transit. 2019 May;233(5):537-49. https://doi.org/10.1177/0954409718800527 
8. Koc W, Specht C, Chrostowski P, Szmagliński J. Analysis of the possibilities in railways shape assessing using GNSS mobile measurements. Wilde K, Niedostatkiewicz M, editors. MATEC Web Conf. 2019;262:11004.

https://doi.org/10.1051/matecconf/201926211004

9. Naganuma Y, Yada T, Uematsu T, Development of an inertial track geometry measuring trolley and utilization of its high-precision data. Int. J. Transp. Dev. Integr., Vol. 3, No. 3 (2019), 271-285. https://doi.org/10.2495/TDI-V3-N3-271-285

10. Specht C, Koc W, Chrostowski P, Szmagliński J, Accuracy assessment of mobile satellite measurements in relation to the geometrical layout of rail tracks. Polish Academy of Sciences. Metrol. Meas. Syst., vol. 26 (2019) No. 2, pp. 309-321. https://doi.org/10.24425/mms.2019.128359

11. Specht M, et-al. Testing the positioning accuracy of GNSS solutions during the tramway track mobile satellite measurements in diverse urban signal reception conditions. Energies 2020, 13, 3646.

https://doi.org/10.3390/en13143646

12. Spinsante S, Stallo C, Hybridized-GNSS approaches to train positioning: challenges and open issues on uncertainty, Sensors 2020, 20, 1885. https://doi.org/10.3390/s20071885

13. Weston P, Roberts C, Yeo G, Stewart E. Perspectives on railway track geometry condition monitoring from in-service railway vehicles. Veh. Syst. Dyn. 2015 Jul 3;53(7):1063-91.

https://doi.org/10.1080/00423114.2015.1034730

14. Wilk A, Specht C, Koc W, Karwowski K, Chrostowski P, Szmagliński J, et al. Research project BRIK: development of an innovative method for determining the precise trajectory of a railway vehicle. Transp. Overv. - Przeglad Komun. 2019 Jul 1; 2019(7):32-47.

https://doi.org/10.35117/A_ENG_19_07_04

15. Zhou Y, Chen Q, Niu X, Kinematic measurement of the railway track centerline position by GNSS/INS/Odometer integration. IEEE Access, vol. 7, 2019, pp. 157241-157253.

https://doi.org/10.1109/ACCESS.2019.2946981

Received 2020-04-20

Accepted 2020-07-21

Available online 2020-08-03

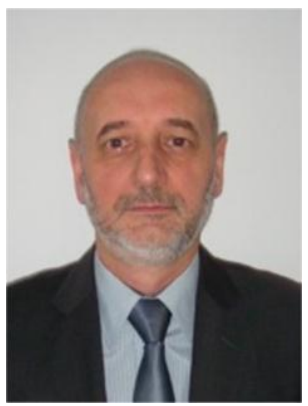

\section{Andrzej WILK}

(IEEE Member) received M.Sc., $\mathrm{PhD}$, and D.Sc. degrees in electrical engineering, respectively from the Gdańsk University of Technology (GUT). With the GUT since 1984, currently as an Associate Professor. His research interests include diagnostics of railway track and electric traction.

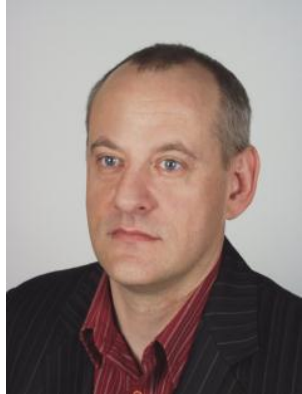

Cezary SPECHT

Professor of technical sciences in the discipline of geodesy and cartography, full professor and head of the Department of Geodesy and Oceanography at the Faculty of Navigation of the Maritime University of Gdynia. The main research activity is geodesy and GNSS (Global Navigation Satellite Systems).

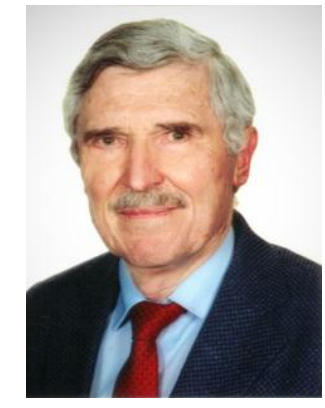

Wladyslaw KOC

Full professor of technical sciences in the discipline of civil engineering and transport. Currently scientific and technical specialist at the Gdańsk University of Technology. His research activity is focused on railway engineering, especially on track geometric layouts analysis.

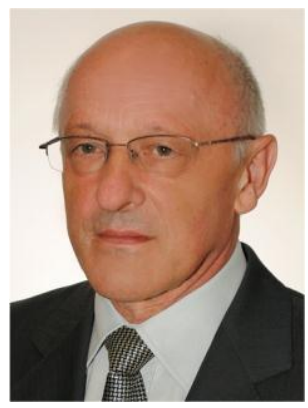

\section{Krzysztof KARWOWSKI}

received M.Sc., PhD, and D.Sc. degrees in electrical engineering, respectively from the Gdańsk University of Technology (GUT). With the GUT since 1975, currently as an Associate Professor. His area of research is focused on technical diagnostics of vehicles and transport infrastructure.

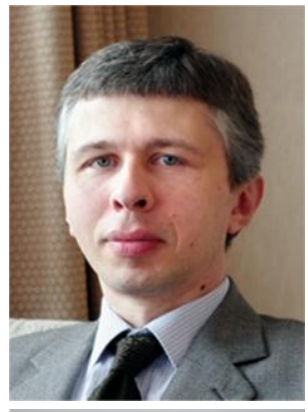

Jacek SKIBICKI

received M.Sc., $\mathrm{PhD}$, and D.Sc. degrees in electrical engineering, respectively from the Gdańsk University of Technology (GUT). He works on GUT since 2000, currently as an Associate Professor. His area of research is focused on metrology and diagnostics of railway infrastructure.

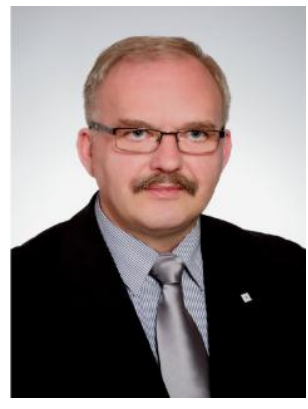

\section{Krzysztof CZAPLEWSKI}

received M.Sc., $\mathrm{PhD}$ degrees in geodesy and cartography from the Polish Naval Academy and D.Sc. degree from University of Warmia and Mazury. Currently as an Associate Professor in Gdynia Maritime University. His area of research is focused on theoretical and application problems of navigation data.

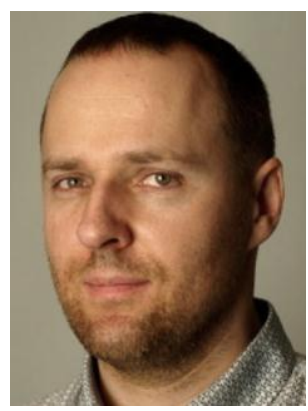

Piotr CHROSTOWSKI

received M.Sc. and $\mathrm{PhD}$ degrees in civil engineering, respectively from the Gdańsk University of Technology (GUT). With the GUT since 2008, currently as an Assistant Professor. His area of research is focused on railway engineering, especially on track geometric layouts analysis. 


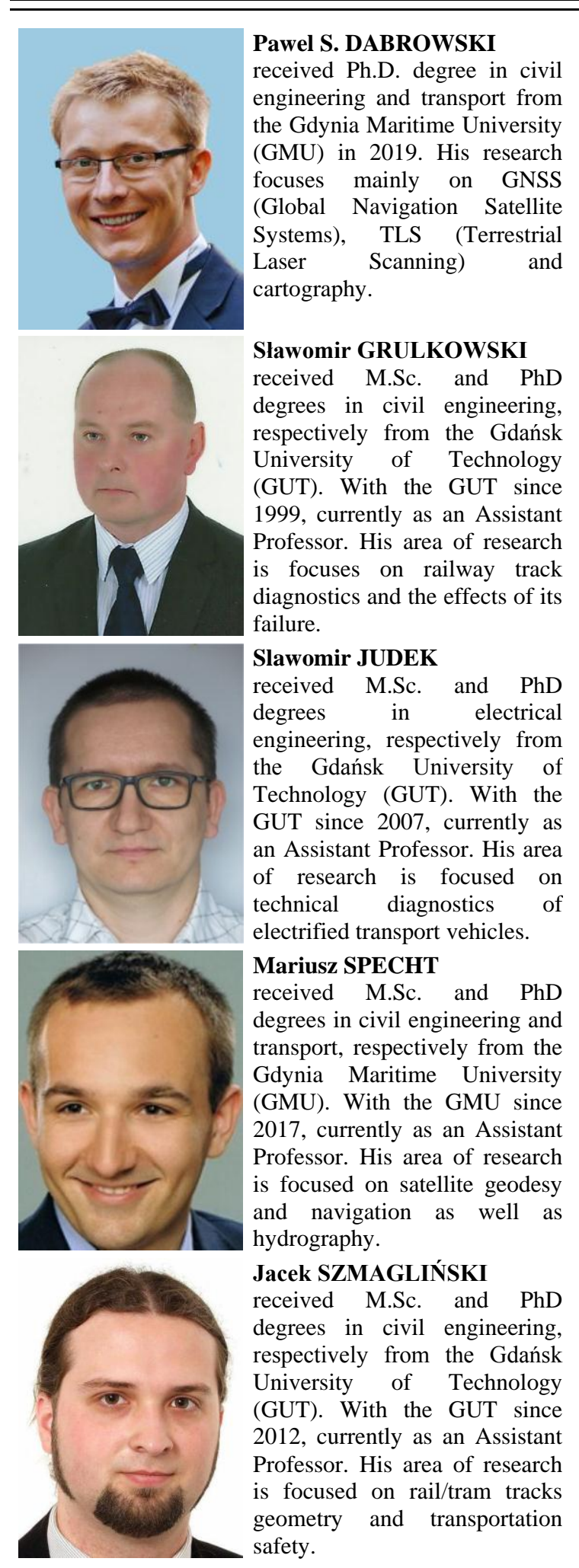

